\title{
Evaluating the effects of land use and strategies for parking and transit supply on mode choice of downtown commuters
}

\author{
Seyed Amir H Zahabi \\ McGill University ${ }^{a}$
}

\section{Philippe Barla}

Centre for Data and Analysis in Transportation (CDAT) Université Laval ${ }^{d}$

\author{
Luis. F. Miranda-Moreno \\ McGill University ${ }^{b}$
}

\author{
Zachary Patterson \\ Concordia University ${ }^{c}$
}

\author{
Centre for Data and Analysis in Transportation (CDAT) Université Laval do
}

\begin{abstract}
Metropolitan regions around the world are looking for sustainable strategies to reduce motor-vehicle traffic congestion, energy consumption, and emissions. These strategies include land-use policies as well as improvements to public transit services. This empirical work aims at studying the potential impact of land use (LU), public transit supply (PT), and parking pricing strategies on the mode choice of commuters living in the commuter rail line catchments in the Montreal (Canada) region. It makes use of an econometric modeling approach with both transportation mode choice and neighborhood type choice as simultaneous decisions, in order to take into account the endogeneity of these choices. The neighborhood choices are represented by neighborhood typologies derived from a cluster analysis using land use and transit supply indicators (population density, land use mix, and bus transit supply). As part of the outcomes of this study, the elasticities of mode choice with respect to commuter-transit fees, travel time reductions, and hourly parking costs are estimated. From the results, it is observed that a reduction of 10 percent in the transit fee or relative travel time would increase mode split by 10 percent and 3 percent respectively. The effect of age on both mode choice and neighborhood choice is also estimated. The individual and household structure factors associated with mode choice and/or residential neighborhood choice are also identified. Commuter age affects both outcomes. Income and gender affect mode choice while car ownership and the presence of children are linked to neighborhood choice.
\end{abstract}

Keywords: Commuting; Mode choice; Parking fees; Public transit

\section{Introduction}

The complexity and significance of the relationships between land use (LU), public transit accessibility (PT), parking pricing, and travel behavior outcomes (such as mode choice) have been identified in transportation planning and research for decades. The intricacy of these relationships is due to several factors:

There are several dimensions that define land use (population density, land use mix, road network connectivity, etc), public transit accessibility (number of lines, headway, distance to stops), parking policies (parking fees, capacity, free parking at work), and travel behavior (mode choice, distance traveled, number of trips, residential location choice, emissions, etc.).

\footnotetext{
a seyed.zahabi@mail.mcgill.ca

b luis.miranda-moreno@mcgill.ca

c zachary.patterson@concordia.ca

dphilippe.barla@ecn.ulaval.ca
}

There is increasing evidence for the endogeneity of mode choice and residential location choice. In practice, and often in research, residential location and mode choice are assumed to be independent choices. Residential location choice has been modeled as a function of demographics, the housing market and housing prices, employment location, and accessibility measures, while mode choice has been modeled as a function of mode-specific attributes (e.g., monetary cost, in-vehicle travel time and waiting times), sociodemographics (age, income, car ownership), and land-use or built-environment characteristics of the residential location.

There is, however, increasing evidence that households choose neighborhoods that allow them to pursue their activities using modes that are compatible with their sociodemographic characteristics (e.g., income, car ownership, life cycle) and travel preferences (e.g., preference for the use of a particular mode or short commuting travel times). This phe-

Copyright 2012 Seyed Amir H Zahabi, Luis. F. Miranda-Moreno, Zachary Patterson, Philippe Barla. Licensed under the Creative Commons Attribution - NonCommercial License 3.0. 
nomenon is generally referred to as residential self-selection or residential sorting (for additional details, see Transportation Research Board (2009)). Ignoring the dependence of these choices, when they are not independent, can result in the identification of false causal effects of LU attributes on mode choice and lead to misguided policy prescriptions. In order to correctly assess the impact of LU on mode and residential location choice, the self-selection issue has to be taken into account. This can be done by modeling jointly the two outcomes, residential location and mode choice, as endogenous choices (Transportation Research Board 2009).

Accordingly, the objectives of this paper are twofold: 1) to investigate the impact of commuter-transit service attributes, parking cost, and residential neighborhood types on commuter-transit mode choice, and 2) to model simultaneously the two choices (transportation mode and residential neighborhood location), explicitly accounting for residential self-selection.

The paper starts with a literature review looking at the link between land use, parking fees, residential location choice, mode choice, and residential self-selection. The second section contains a description of the methodology adopted. This is followed by a description of the data used and developed for the analysis. The next two sections describe the statistical analysis adopted and the resulting models. A discussion and conclusion finishes the paper, with special attention given to the practical applications of the research.

\section{Literature review}

The transportation literature on land use, transit accessibility, parking pricing, and mode choice, including the self-section issue, is abundant. This section provides a brief literature review considering the main elements of these research streams which have been studied using different approaches, cities, and sources of data.

\subsection{Land use, public transit accessibility, and their effect on travel behavior}

A vast body of literature over the past two decades has analyzed the link between LU and travel behavior. Among these studies are at least six comprehensive reviews of the literature (Badoe and Miller (2000); Crane (2000); Ewing and Cervero (2001); Handy et al. (2005); Cao et al. (2008); Gómez-Ibáñez et al. (2009)). Much of this research has concentrated on the impact of land use attributes on mode choice. Many studies have found that land use characteristics have a significant im- pact on mode choice decisions. ${ }^{1}$ It is, however, interesting to note that not all of the past studies have reported the significant influence of LU attributes. For example, Crane and Crepeau (1998) and Hess (2001) found no relationship between LU and mode choice decisions. Kitamura et al. (1997), among others, studied the impact of LU and socio-demographic characteristics on the number and share of each mode in trips made, and reported that demographic variables have a bigger impact on travel mode choice than LU attributes. Cervero (2002) examined mode choice behavior in Maryland and concluded that the effects of LU types alone tend to be more limited than those of LU mix (or land use mix indices) on mode choice travel decisions.

\subsection{Residential self-selection}

Several of the studies mentioned above ignore the issue of residential self-selection when estimating the impact of $\mathrm{LU}$ variables on travel behavior. However, this is not always the case. One of the first studies to tackle the question of residential self-selection was performed by Boarnet and Sarmiento (1998). They adopted an instrumental variables approach by using the percentage of buildings built before 1945, percentage of buildings built between 1945 and 1985, the percentage of foreign residents, and the percentage of residents more than 65 years old as instruments for residential density and they did not find any stable link between residential density and vehicle miles traveled (VMT).

While not explicitly about residential location and mode choice, Bhat and Guo (2007) used data from the San Francisco Bay area to build a joint model of residential location and number of vehicles per household. Their model takes into account the self-selection effect (by allowing correlation between the error terms in their equations), but found no significant effects even after controlling for a rich set of explanatory variables. They did find statistically significant but quantitatively small impacts of LU measures on household car ownership.

Brownstone and Golob (2009) modeled the joint choice of residential density and VMT to control for potential selfselection effects. They included a rich data set using the California subsample of the 2001 National Household Travel Survey. Unlike previous researchers, they also modeled vehicle fuel consumption. They concluded that the effects of increas-

\footnotetext{
1 See Frank and Pivo (1994); Ewing et al. (1994); Handy (1996); Cervero and Wu (1997); Cervero and Kockelman (1997); Kockelman (1997); Badoe and Miller (2000); Crane (2000); Ewing and Cervero (2001); Rajamani et al. (2003); Rodriguez and Joo (2004); Zhang (2004); Ewing and Cervero (2010).
} 
ing residential density on the reduction of VMT or greenhouse gas (GHG) emissions from residential vehicles are very small.

Again, while not explicitly focusing on residential location and mode choice, Eluru et al. (2010) built a joint econometric model system for household residential location and vehicle type/usage choices. In this system they controlled for selfselection issues in these choices. They concluded that there is significant dependence between these choice dimensions and that self-selection effects cannot be ignored when modeling land-use and travel behavior interactions.

Ewing and Cervero (2010) conducted a meta-analysis of the literature on the relationship between the built environment and travel extent at the end of 2009 in order to draw generalizable conclusions for practice. They focused on quantifying effect sizes, updating their earlier work, including additional outcome measures, and addressing the methodological issue of self-selection.

Miranda-Moreno et al. (2011) considered the relationship between urban form, public transit accessibility, and daily mobility for residents of the metropolitan region of Quebec City. They implemented a model of two simultaneous equations, taking into account the interaction between vehicle ownership and choice of household location as an explanatory endogenous variable for total distance traveled by respondents. They concluded that a simultaneous model taking into account endogeneity of the interaction between ownership of vehicles and household choice better explains distance traveled than a simple linear regression model.

\subsection{Parking pricing}

Parking costs are an important factor in travel mode choice. Wilson (1992) found that between 25 and 34 percent fewer vehicles were used to drive to work when drivers had to pay for parking compared to when they could park for free. A comprehensive study of a strategy to reduce single-occupancy commuter trips was reported by Bianco (2000). The project was a major part of a travel demand management (TDM) package in which on-street parking meters and discounted transit passes were also introduced. A before-and-after survey of 1000 employees found that the main shift was in commuters driving alone (7\%), with the "after" drive-alone share lowering to 56 percent of total commute trips. Carpooling trips increased by 38 percent resulting in an "after" market share of 17 percent of all commute trips.

Hess (2001) studied the effect of free parking on mode choice and parking demand. A multinomial logit model was used to evaluate the probabilities of commuters with or with- out free parking at work choosing to: drive alone, ride in a carpool, or use transit for the trip to work in the central business district (CBD) of Portland, Oregon. He found that when the cost of free parking was increased to $\$ 1$, the modal shares for solo driver and carpool decreased by 1 percent and 4 percent, respectively, while the share for public transit increased by 5 percent.

In another study, Washbrook et al. (2006) estimated greater Vancouver's commuters' mode choice in response to parking and road pricing policies. They found that by implementing the parking and road pricing (free road and parking was replaced by a $\$ 1$ fee for parking and $\$ 1$ road pricing), the probability of choosing to drive alone to work decreased by 8 percent.

Hensher and King (2001) used a stated preference survey of car drivers and public transport users at a number of parking locations, public transit interchanges, and shopping centers in the Sydney central business district (CBD). They concluded that a 1 percent increase in hourly parking rates results in a 0.541 percent reduction in the probability of choosing to park in a sheltered parking lot, a 1.015 percent reduction in the probability of choosing to park elsewhere in the CBD and a 0.476 percent reduction in the probability of parking on the margins of the CBD.

Despite the rich literature on residential location choice and the influence of LU on travel behavior, there remain some research gaps, in particular:

1. There is relatively little research treating household location and mode choice as a simultaneous, endogenous process accounting for residential self-selection bias;

2. Very little research has been done that looks at commuters' mode and residential location choices while also considering parking pricing strategies;

3. Very few studies have considered neighborhood typologies generated based on LU and PT indicators to represent household location choices;

4. Little work has been done to look at the determinants and their elasticities of travel demand of commuters living in rail catchment areas.

To provide some empirical evidence related to these issues, this study uses a simultaneous modeling method that fills these gaps. 


\section{Methodology}

This paper examines the impact of LU and PT characteristics represented by neighborhood typologies, in the context of an endogenous modeling system of residential location and mode choice of commuters residing in the railway catchments of Montreal's suburban rail system. For this, a neighborhood typology classification is developed for the city of Montreal based on LU and PT variables. This approach is based on the idea that household location and mode choice are intimately linked.

In this model, neighborhood choice is a function of socio-demographic characteristics, whereas mode choice is directly influenced by neighborhood choice, parking management strategies (at work-place destination), and sociodemographics (see Fig. 1). It is assumed that these decisions are made jointly, and since neighborhood type appears in the mode choice utility function, it is an endogenous variable.

$$
\begin{aligned}
M & =f\left(X, T, P, K, \varepsilon_{1}\right) \\
K & =g\left(X, \varepsilon_{2}\right)
\end{aligned}
$$

Where:

$M$ : Mode chosen by commuter (personal automobile $=$ 0 , or transit $=1$ )

$K$ : neighborhood type chosen by a given commuter

$X$ : socio-economic characteristics of individual and household (e.g., age, gender, income, car ownership, etc.)

T: Transportation mode attributes (fare, in-vehicle travel times, waiting time, etc.)

\section{$P$ : Parking strategies (e.g. pricing and capacity)}

$\varepsilon_{1}$ and $\varepsilon_{2}$ : correlated errors representing unobservable factors that influence mode and neighborhood choice

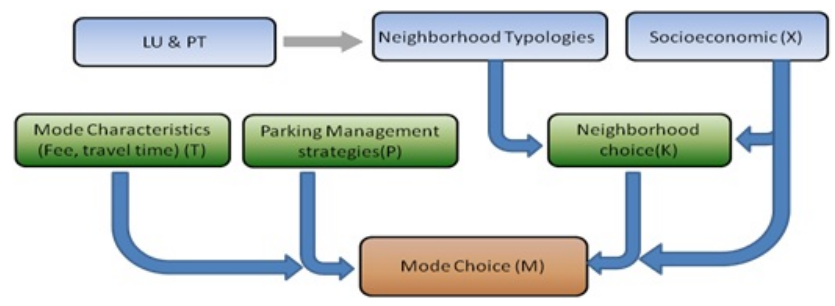

Figure 1: Household location and mode choice.

\section{Data}

Several different types of data from different sources are used for this empirical application, including a subsample of commuting trip data from an origin-destination survey, sociodemographics, travel times by mode, land use, and parking data. The details of each particular source of data are provided below.

\subsection{Origin-destination survey}

Data for the mode choice model come primarily from the 2003 Montreal Origin-Destination (OD) survey. In 2003, 71400 households were surveyed, accounting for 4.7 percent of the households of the region. This represented 366300 (unexpanded ${ }^{2}$ ) trips over a 24-hour period, 92000 of which took place in the morning peak period. This research concentrated on commuters with a morning peak trip originating in one of the five commuter rail catchment areas and whose destination was downtown in the morning peak. The commuter rail catchment areas (as determined by the Agence métropolitaine de transport $^{3}$ (AMT)) cover suburban communities found along the commuter rail lines. As such, the population of interest was those workers for whom commuting by public transit (primarily train) or car was a possibility. This sample consisted of 3710 observations. A map of observations and the railway catchments is found in Figure 2.

\subsection{Mode choice data}

Public transit travel times were obtained from the AMT and were simulated using the entirely disaggregate public transit assignment software MADIGAS. ${ }^{4}$ Public transit fees, based on origin, destination and simulated transit itinerary, were also obtained from the AMT. Automobile travel times for each trip were obtained from the Quebec Ministry of Transportation using their modeling system known as MOTREM ${ }^{5}$ which employs the EMME travel demand forecasting system for automobile traffic assignment.

For modeling purposes all transit modes (commuter rail, metro, and bus) were grouped together.

\footnotetext{
${ }^{2}$ Not multiplied by the expansion factor for each trip, in order to represent the whole population.

${ }^{3}$ Agency responsible for operation of commuter rail lines and the coordination of public transportation planning in the Greater Montreal Region.

${ }^{4}$ http://www.transport.polymtl.ca/logiciel.htm

${ }^{5}$ Montreal region transport model for 2003 (Modèle de transport de la région de Montréal 2003).
} 


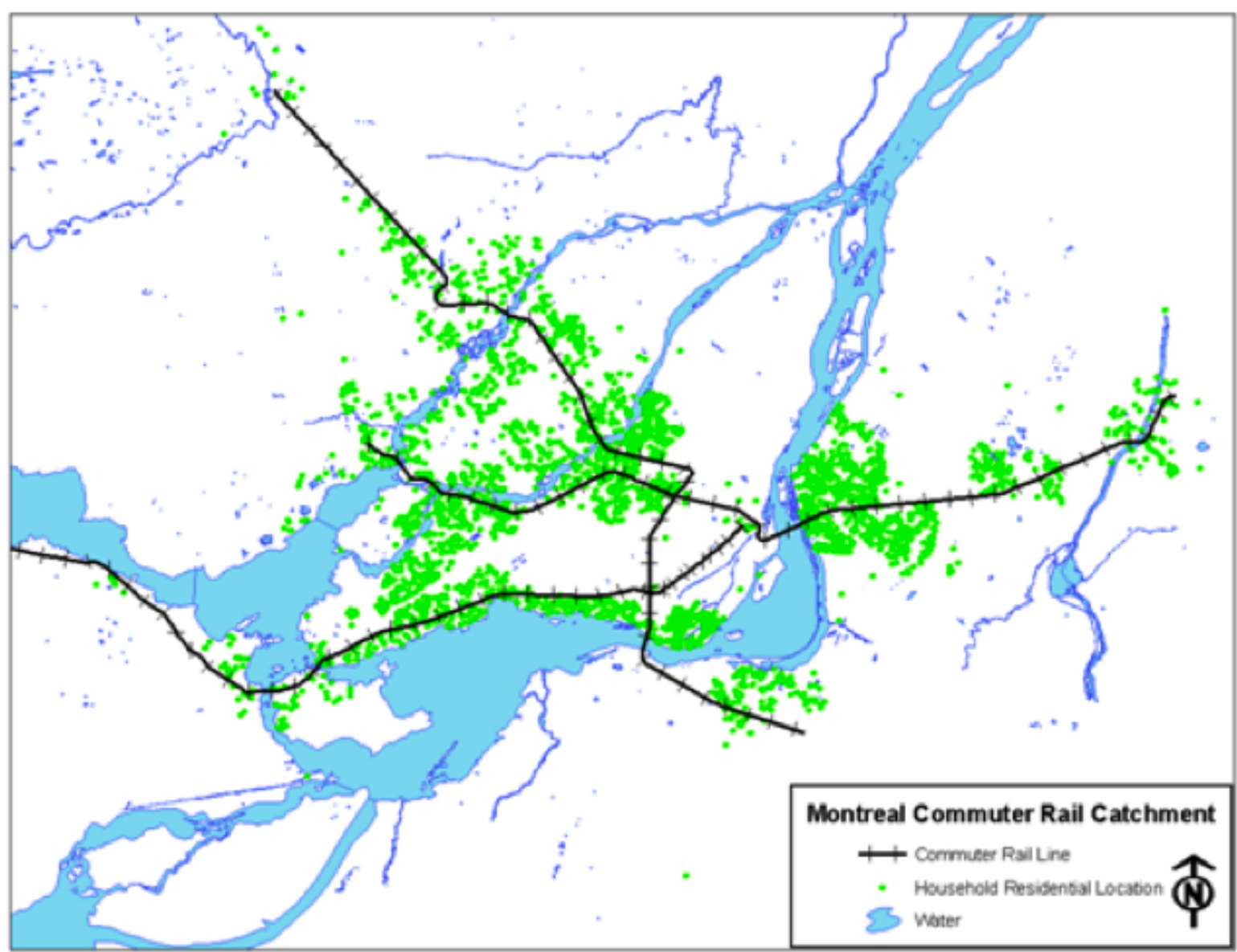

Figure 2: Household location and commuter rail catchment areas. 


\subsection{Population density, land use mix, and PT accessibility}

In order to create neighborhood typologies, three builtenvironment indicators were used: population density, land use mix, and a simple measure of PT accessibility. The data collection approach is based on a $500 \mathrm{~m}$ grid covering the entire greater Montreal region. Each household from the 2003 OD survey is assigned the characteristics of the cell in which it is situated, as well as the characteristics of the eight surrounding cells (see Figure 3). Thus, population density around the household is calculated as the sum of the population in the nine cells divided by the area of the nine cells. Population data used are from Statistics Canada (2001).

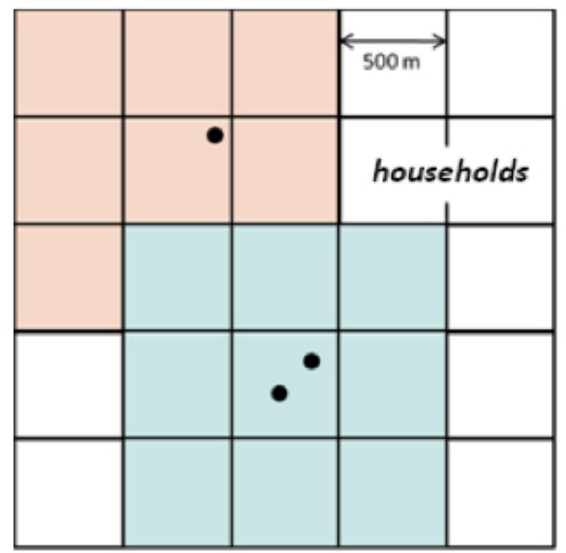

Figure 3: $500 \mathrm{~m}$ grid approach.

Land use mix (entropy) was calculated using data from DMTI Spatial, Inc. The land use mix indicator used is modeled after an entropy index (Frank et al. (2005); Theil and Finizza (1971)), which measures diversity or homogeneity of different land uses in each grid cell. The index is defined using the following equation:

$$
E_{j}=-\sum_{i=1}^{n} \frac{\left[\left(\frac{A_{i j}}{D_{j}}\right) \ln \left(\frac{A_{i j}}{D_{j}}\right)\right]}{\ln (n)}
$$

Where:

$A_{i j}$ : area of land use $i$ in cell $j$

$D_{j}$ : area of cell $j$ excluding water and open area

$n:$ total number of different land uses

In this study, $n=5$ : residential commercial, industrial, institutional, and park. The value of $E_{j}$ varies between 0 and 1 ;
0 corresponds to a homogenous area characterized by a single land use and 1 refers to a "perfect mix" in which all land use types are represented equally. This index has been used in many studies to measure land use mix (Cloutier et al. (2007); Frank et al. (2005)).

The measure of PT accessibility takes into account the number of transit lines (bus, metro, and rail) passing within $500 \mathrm{~m}$ of the household. Finally, the neighborhood typology is generated using a cluster analysis (described below) based on the $\mathrm{LU}$ and PT variables mentioned above.

\subsection{Parking charges and accessibility}

In order to capture the properties of parking in the vicinity of the destination of each individual in the data set, the destination for each trip was geo-coded using ArcGIS. Using the coordinates of the off-road parking lots, these were also included (see Figure 4). Parking costs for a particular destination associated with the closest and cheapest parking lot (network distance) to the observed destination were considered. The number of parking spaces was also considered; however, the results with and without this factor were similar.

\section{Analysis}

\subsection{Neighborhood cluster analysis}

The neighborhood cluster analysis carried out in this research is similar to that presented in Lin and Long (2008), Riva et al. (2008), and more recently Miranda-Moreno et al. (2011). The $k$-means statistical cluster analysis technique is used in order to regroup households into $\mathrm{k}$ homogenous clusters according to LU and PT characteristics. This was done with the $k$ means function in STATA. The goal of using this technique is to maximize inter-cluster variation while minimizing intracluster variation. The objective is therefore to assemble commuter households into $k$ subgroups having similar population densities, land use mixes (entropy), and PT accessibilities.

Several attempts were made with different numbers of clusters and finally it was found that four clusters were a satisfactory number (four different types of neighborhoods), where each one had an acceptable number of households and sufficient variation between clusters. The characteristics of the four clusters (neighborhoods) are described in Table 1. Figure 5 shows the location of each neighborhood cluster.

As can be seen in Table 1, the clusters can be characterized according to three indicators as follows:

Cluster one (transit-oriented development) is characterized by the best PT accessibility, highest density, and highest level 


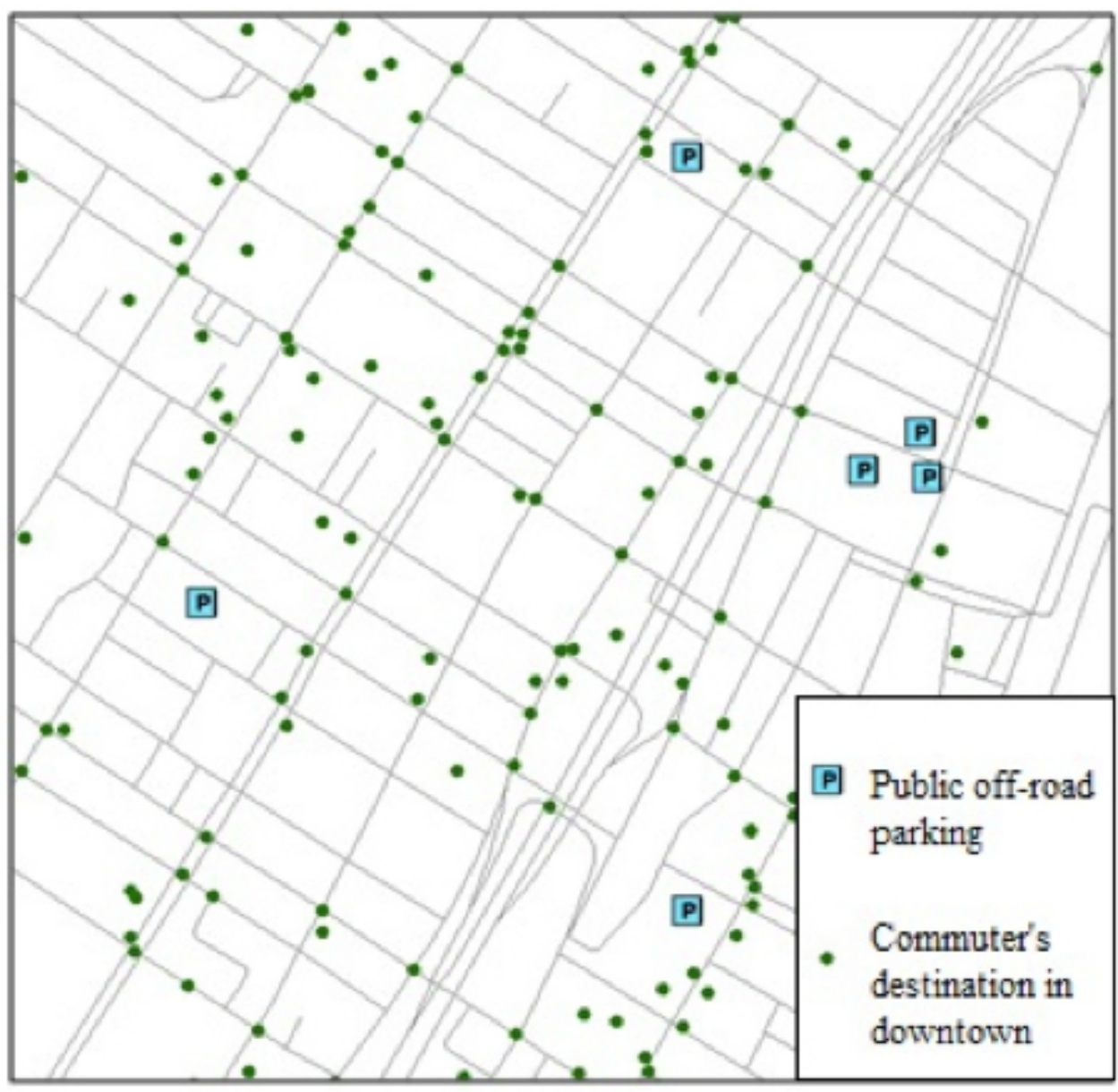

Figure 4: Downtown parking locations and destinations of commuters. 


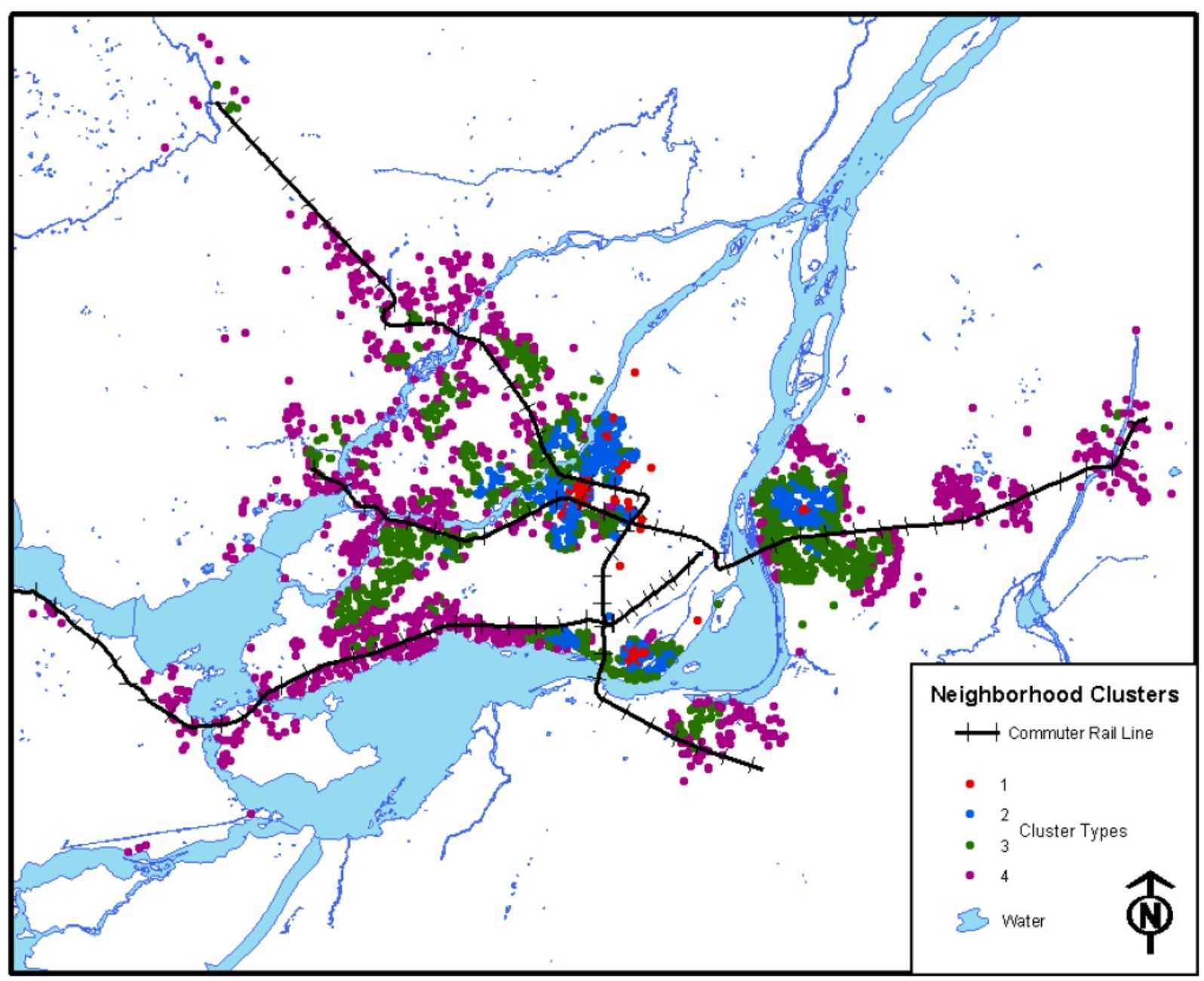

Figure 5: Neighborhood clusters for households in the data set. 
of land use mixing in the region. This primarily comprises neighborhoods situated in the dense residential areas of downtown or catchment suburb areas with high proximity to the main transit axes and access to a rich variety of retail and services. $^{6}$

Cluster two groups households outside of downtown having relatively good PT access. It also includes neighborhoods located along transit axes. This cluster has the second highest density and level of land-use mixing.

Cluster three neighborhoods have moderate transit accessibility compared to clusters 1 and 2 . The density and land use mix for this cluster is around the average for all clusters.

Cluster four (periphery) includes all areas with poor PT accessibility, low density, and homogenous land use. Households in this cluster are mostly situated in the periphery or too far from PT lines to have satisfactory accessibility. Cluster four represents the average characteristics of the greater proportion of households in the Montreal City region.

\subsection{Descriptive statistics}

A statistical summary of the explanatory variables used in the analyses is presented in Table 2.

\subsection{Statistical modeling}

The next step is to estimate the two simultaneous equation models using the approach proposed by Deb and Seck (2009) and Deb and Trivedi (2006). As specified in the methodology section, the choice of residential neighborhood is modeled simultaneously with the choice of transportation mode as a binary outcome (car and transit). That is, the individuals select simultaneously where to live and what mode of transport they would use to get from a given origin to a particular destination. According to the four neighborhood typologies previously defined and whether the individual used a personal automobile or public transit for their trip, four different choices are set up for residential location and two for transportation modes. Equations 4 and 5 present the utility functions for the different choices, taking into account the self-selection phenomenon between household location choice and mode choice.

$$
\begin{aligned}
& M_{q i}=\alpha_{q} x_{q i}+\sum_{j=1}^{4} \mu_{j} k_{i j}+\sum_{j=1}^{4} \lambda_{j} l_{i j}+\varepsilon_{q i} \\
& N_{i j}=\beta_{j} z_{i}+\delta_{j} l_{i j}+\eta_{i j} \quad j=1, \ldots, 4
\end{aligned}
$$

${ }^{6}$ NB: Some of these people, while not residing in the railway catchments, had a morning peak trip originating in one of the railway catchments.
Where:

$M_{q i}$ : Utility function of mode choice of individual $i$ ( $q=0,1$ personal automobile and transit)

$N_{i j}$ : Utility of cluster choice $j$ for individual $i, j=$ $1, \ldots, 4$

$x_{q i}$ : socio-economic or mode characteristics of individual $i$ (age, income, travel time, cost) for mode $q$ and individual $i$

$z_{i}$ : socio-economic characteristics of individual $i$ associated to cluster choice

$k_{i j}$ : dummy variables representing neighborhood cluster $j$ for the household of individual $i$

$l_{i j}$ : Latent explanatory variable of unobserved heterogeneity by endogenous variables (Follows a normal distribution)

$\varepsilon_{i}:$ random independent error (Logistic distribution)

$\eta_{i j}:$ random independent error (Logistic distribution)

$\alpha, \beta, \delta, \lambda, \mu:$ model parameters (vectors)

Note that correlation among the outcomes is considered through the unobserved latent variable $l_{i j}$ that appears in both utility functions. The model is estimated with STATA 10.1 using the estimation method proposed by and Deb and Trivedi (2006). This estimation method models multinomial treatments and a binary outcome using maximum simulated likelihood. In this case, the mode choice variable is represented by a binary outcome while the treatment choice (neighborhood type) is assumed to follow (conditionally on the latent factors) a mixed multinomial logit (MMNL) structure defined as:

$$
\operatorname{Pr}\left(K_{i j} \mid x_{i}, l_{i j}\right)=\frac{\exp \left(\beta_{j} Z_{i}+\delta_{j} l_{i j}\right)}{\sum_{k}^{j} \exp \left(\beta_{k} z_{i}+\delta_{k} l_{i k}\right)}
$$

With the normalization structure $\beta_{4}=0$ and $j=$ $1,2,3,4$. The model parameters are then estimated using maximum simulated likelihood and the simulator uses Halton sequences (Deb and Trivedi 2006). In our model, the mode choice outcome variable has a logistic distribution. The simultaneous model considers household location choice as an endogenous variable explaining mode choice by individuals and thereby takes into account potential self-selection bias. Using 
Table 1: Characteristics of the four clusters.

\begin{tabular}{|c|c|c|c|c|c|}
\hline & \multicolumn{2}{|c|}{ Observations } & \multicolumn{3}{|c|}{ Average } \\
\hline Cluster 1 & 132 & 3.56 & 6.76 & 8.28 & 0.66 \\
\hline Cluster 4 & 1598 & 43.07 & 1.96 & 1.59 & 0.45 \\
\hline Total/average & 3710 & 100.00 & 3.47 & 3.12 & 0.49 \\
\hline
\end{tabular}

this estimation method in order to be able to identify the variances of the unobserved factors, normalization is required on either $j$ or $\delta_{j}$. It is assumed that $\delta_{j}=1$, and $\lambda_{j}$ is a free parameter estimated by the model.

\section{Results}

\subsection{Mode choice model}

Table 3 presents the $\mathrm{AIC}^{7}$ values for three models as a way to compare our simultaneous model with two separate binary logit and multinomial logit (MNL) models. The likelihood ratio (LR) test ${ }^{8}$ for exogeneity of the models is also provided. Comparing the models, we see that the AIC value of the simultaneous model is smaller than the independent model (12977 vs. 13036). This indicates a better fit of the simultaneous model compared to the two separate logit models. Also, the likelihood ratio (LR) test is 63.0 and statistically significant different from 0 , indicating that the null hypothesis of exogeneity is overwhelmingly rejected at any level of significance.

Table 4 shows the results of the simultaneous model of mode and household location choice versus a simple binary logit model that is not estimated jointly with neighborhood choice. In these models, as explained in the statistical modeling section, the outcome of the mode-choice part takes values of 1 for PT and 0 for personal automobile.

\footnotetext{
${ }^{7}$ Akaike's information criterion (AIC) is a measure of the goodness of fit of an estimated statistical model

AIC $=-2 * \ln ($ likelibood $)+2 * k$, where $k=$ estimated variables + constants.

${ }^{8}$ The LR test for exogeneity of treatment is a test for a joint hypothesis that all values of $\lambda$ are equal to zero. It follows a Chi-square distribution with $q=3$ (number of treatments).
}

As suggested by the literature review, socio-demographic variables have statistically significant impacts on mode choice. In this empirical study, age, income, and gender appear to be significant. From these variables, the highest elasticity is attributed to sex (for female), suggesting that being male decreases the probability of choosing PT by 62 percent on average. For age, its coefficient implies that every year of increase in age is associated with a 1 percent decline in the chance of using PT is observed. Income also has a negative effect on choosing PT. On average, an increase of $\$ 10000$ in annual income is associated with a 10 percent reduction in probability of using PT.

Regarding the mode choice attributes, the transit fee, the difference in travel time, and hourly parking cost resulted in statistically significant and right-sided coefficient estimates. As expected, an increase in the transit fare reduces the probability of commuters selecting transit modes. Based on its elasticity, a 10 percent increase in PT fee would on average result in a 10 percent reduction in probability of choosing PT. Difference in travel time $\left(\Delta_{t}=\right.$ [travel time by car] - [travel time by PT]) has an inverse effect on the likelihood of selecting PT. In other words, if the absolute value of $\Delta_{t}$ increases by 10 percent, the chance of selecting PT declines by 3 percent. Finally, the only factor in our model that positively affects the probability of PT being selected is parking cost. A $\$ 1$ increase in the hourly parking cost for personal automobiles implies the probability of using PT instead of car increases by 5 percent. This is consistent with some estimates in the literature (e.g. Hess 2001).

For the neighborhood endogenous variables, individuals living in Clusters 1 and 2 who are located in central neighborhoods are more likely to choose PT for trips than those living in the periphery. For these individuals, the probability of using PT increases by 13 percent and 14 percent, respectively. For those households located in cluster 3 the impact of house- 
Table 2: Summary statistics for explanatory variables $(n=3710)$.

\begin{tabular}{|c|c|c|c|c|c|}
\hline Variable & Mean & Std. dev. & Min. & Max. & Variable type \\
\hline \multicolumn{6}{|l|}{ Mobility } \\
\hline Mode choice $(0=$ auto, $1=$ transit $)$ & 0.57 & 0.49 & 0.00 & 1.00 & Binary \\
\hline PT access time (min) & 10.31 & 6.81 & 0.00 & 46.74 & Continuous \\
\hline PT waiting time ( $\mathrm{min})$ & 23.57 & 10.20 & 6.50 & 76.25 & Continuous \\
\hline PT in vehicle time ( $\mathrm{min})$ & 34.07 & 14.59 & 4.96 & 107.00 & Continuous \\
\hline (Auto total time $-\mathrm{PT}$ total time) & -18.36 & 14.45 & -96.38 & 19.89 & Continuous \\
\hline Public transit fee & 98.52 & 28.81 & 39.00 & 222.00 & Continuous \\
\hline Parking hourly cost & 3.19 & 2.57 & 0.00 & 7.60 & Continuous \\
\hline Parking capacity & 204.82 & 244.48 & 14.00 & 1252.00 & Continuous \\
\hline \multicolumn{6}{|l|}{ Land use } \\
\hline Cluster $1-4$ & 3.18 & 0.84 & 1.00 & 4.00 & Categorical \\
\hline PT accessibility & 3.47 & 4.45 & 0.00 & 34.00 & Continuous \\
\hline Density (people/km2) & 3124.09 & 1799.98 & 0.00 & 14243.03 & Continuous \\
\hline Entropy index & 0.49 & 0.192 & 0.00 & 0.999 & Continuous \\
\hline \multicolumn{6}{|l|}{ Household characteristics } \\
\hline Number of vehicles & 1.61 & 0.84 & 0.00 & 12.00 & Continuous \\
\hline Number of people & 3.03 & 1.23 & 1.00 & 12.00 & Continuous \\
\hline Number of children & 0.63 & 0.91 & 0.00 & 7.00 & Continuous \\
\hline Income $(1 \text { to } 6)^{a}$ & 4.07 & 1.51 & 1.00 & 6.00 & Categorical \\
\hline Number of workers & 1.73 & 0.70 & 0.00 & 6.00 & Continuous \\
\hline \multicolumn{6}{|l|}{ Individual characteristics } \\
\hline Age & 39.5 & 11.98 & 5.00 & 84.00 & Continuous \\
\hline$(\mathrm{Age})^{2}$ & 1703.79 & 965.58 & 25.00 & 7056.00 & Continuous \\
\hline Age $<35$ years & 0.37 & 0.48 & 0.00 & 1.00 & Dummy \\
\hline Age $35-50$ years & 0.47 & 0.50 & 0.00 & 1.00 & Dummy \\
\hline Age $50-64$ years & 0.21 & 0.41 & 0.00 & 1.00 & Dummy \\
\hline Age $>64$ years & 0.02 & 0.13 & 0.00 & 1.00 & Dummy \\
\hline $\operatorname{Sex}(0=$ female, $1=$ male $)$ & 0.49 & 0.50 & 0.00 & 1.00 & Dummy \\
\hline Driver's license $(1=$ yes, $0=$ no $)$ & 0.9 & 0.30 & 0.00 & 1.00 & Dummy \\
\hline Full-time & 0.83 & 0.37 & 0.00 & 1.00 & Dummy \\
\hline Part-time & 0.03 & 0.17 & 0.00 & 1.00 & Dummy \\
\hline Student & 0.01 & 0.11 & 0.00 & 1.00 & Dummy \\
\hline Retired & 0.11 & 0.32 & 0.00 & 1.00 & Dummy \\
\hline Other & 0.01 & 0.11 & 0.00 & 1.00 & Dummy \\
\hline
\end{tabular}

${ }^{a}$ Income ranges for each category (Canadian dollars): $1=(<\$ 20,000) ; \quad 2=(\$ 20,000-\$ 39,999) ; \quad 3=(\$ 40,000-\$ 59,999)$; $4=(\$ 60,000 \$-\$ 79,999) ; 5=(\$ 80,000-\$ 99,999) ; 6=(>\$ 100,000)$. 
Table 3: AIC comparison (Simultaneous model vs a binary logit and MNL model).

\begin{tabular}{lrll}
\hline & \multirow{2}{*}{ AIC } & \multicolumn{2}{c}{ LR test } \\
\cline { 3 - 4 } & & Coef. & P-value \\
\hline $\begin{array}{l}\text { Binary logit } \\
\text { (for the mode choice) }\end{array}$ & 4716 & - & - \\
$\begin{array}{l}\text { MNL (for the cluster choice) } \\
\text { Binary logit + MNL } \\
\text { (sum of rows 1 and 2) }\end{array}$ & 8320 & - & - \\
$\begin{array}{l}\text { Simultaneous multinomial } \\
\text { treatment model } \\
\text { (used in this study) }\end{array}$ & 13036 & - & - \\
\hline
\end{tabular}

hold location on mode choice is negative in comparison to the reference case but this is not statistically significant.

\subsection{Household location choice model}

Table 5 presents the household location choice model. In this case, households are divided into four categories based on the cluster (neighborhood) in which they are located. Thus, it is possible to consider the effect of household location on their mode choice. Cluster 4, which also represents the households in the periphery, is designated as the reference group.

With respect to household location choice, Clusters 1 and 2, which represent neighborhoods with the highest PT accessibility, population density, and greatest land use mix (entropy), and which are basically situated on central neighborhoods, are chosen primarily by individuals under 35 or over 64 years of age (although this is not statistically significant for the over-64 age variable). In fact, being less than 35 years old increases the chance of residing in Cluster 1 by 58 percent and in Cluster 2 by 30 percent. This could be due to the fact that universities and jobs are mostly located in central neighborhoods and downtown, and that younger people prefer to be close to these points. The choice to live in Cluster 3 is more likely for people between 50 and 64 years of age. Actually the probability of an individual 50-64 years old choosing neighborhood type 3 over 4 is about 12 percent higher.

The increase in number of cars per household has a negative effect in choosing any cluster relative to the omitted category (Cluster 4 or periphery). For example, by increasing the household's number of cars by one, the probability of that household residing in Cluster 1 is decreased by 59 percent. The number of children per household has a negative impact on choosing any other neighborhoods than peripheral neigh- borhoods (but this is not statistically significant for Cluster 1). For instance, by adding one child to the family, the probability of that household choosing to live in Cluster $2 \mathrm{com}$ pared to Cluster 4 (omitted category) declines by 20 percent. Number of workers per household positively affects the choice of households to live in clusters other than the reference case (this is not significant for Cluster 1). This could be explained by the households first choosing their work and according to that, the location of their house. For example, by raising the number of workers in households by one, the probability of that household dwelling in Cluster 2 compared to Cluster 4 increases by 29 percent.

\section{Conclusions and limitations}

This paper presents some evidence on the effect of parking pricing, transit service attributes, and neighborhood typologies on mode choice for downtown commuters, controlling for socio-demographics and taking into account residential self-selection. For this study, a large sample of downtown commuters with morning peak-period trips originating in commuter rail catchment areas and with destinations in downtown Montreal was used. This empirical study makes use of a two-equation simultaneous model: one equation for mode choice and the other for residential location choice (represented by neighborhood type).

The main findings of this study are that:

- Both transit mode attributes and parking costs appear to have significant effects on transportation mode choice of downtown commuters. Increasing PT travel time and fares negatively affect the use of PT, while raising the cost of parking increases the probability of choosing PT. More specifically, a $\$ 1$ increase on the parking hourly cost in downtown would imply an increase of 5 percent in the transit modal share for commuters. Moreover, a 10 percent increase in PT fare would represent a 10\% average reduction in the probability of using PT for commuting to downtown.

- As expected, the neighborhood type where commuters live plays an important role in the transportation mode choice even after controlling for socio-demographics and transit attributes. For instance, a downtown commuter living in Cluster 1 or 2 has a 13-14\% higher probability of using transit than a commuter living in Cluster 4 with the same income, gender, age, and commuter train service characteristics. 
Table 4: Mode choice - household location choice.

\begin{tabular}{|c|c|c|c|c|c|c|}
\hline \multirow[b]{2}{*}{ Variables } & \multicolumn{3}{|c|}{ Binary logit model } & \multicolumn{3}{|c|}{ Simultaneous model } \\
\hline & Coef. & P-value & Elasticities & Coef. & P-value & Elasticities $^{\mathrm{a}}$ \\
\hline Cluster 1 & -0.526 & 0.008 & $-18 \%$ & 2.77 & 0.081 & $13 \%$ \\
\hline Cluster2 & -0.205 & 0.073 & $-7 \%$ & 6.001 & 0.028 & $14 \%$ \\
\hline Cluster3 & -0.298 & 0 & $-10 \%$ & -1.184 & 0.218 & $-22 \%$ \\
\hline Cluster4 & \multicolumn{3}{|c|}{ Reference } & \multicolumn{3}{|c|}{ Reference } \\
\hline Age & -0.014 & 0 & $0 \%$ & -0.084 & 0.035 & $-1 \%$ \\
\hline Income & -0.14 & 0 & $-5 \%$ & -0.652 & 0.031 & $-10 \%$ \\
\hline $\operatorname{Sex}(0=$ female, $1=$ male $)$ & -0.544 & 0 & $-19 \%$ & -2.627 & 0.02 & $-62 \%$ \\
\hline Public transit fee ${ }^{b}$ & -0.012 & 0 & $-4 \%$ & -0.065 & 0.021 & $-10 \%$ \\
\hline$\Delta_{t}(\text { Auto total time }-\mathrm{PT} \text { total time })^{\mathrm{c}}$ & 0.023 & 0 & $-1 \%$ & 0.115 & 0.032 & $-3 \%$ \\
\hline Parking hourly cost & 0.034 & 0.013 & $1 \%$ & 0.495 & 0.042 & $5 \%$ \\
\hline Constant & 3.448 & 0 & - & 14.789 & 0.023 & \\
\hline$\lambda$ Clus. 1 & & - & & 0.293 & 0.126 & \\
\hline$\lambda$ Clus. 2 & & - & & -8.928 & 0.016 & \\
\hline$\lambda$ Clus. 3 & & - & & -0.322 & 0.393 & \\
\hline$\lambda$ Clus. 4 & & - & & & Reference & \\
\hline
\end{tabular}

a Elasticities represent the percentage change in the probability of choosing PT: ((new Prob of choosing PT) - (base prob of $\mathrm{PT})$ ) / (base prob of PT).

b This fee is not constant and varies by distance for the commuter rail users.

c Note that the values of $\Delta_{t}$ are negative. This means that as this negative difference increase, the probability of selecting PT is reduced. 
Table 5: Household location choice (cluster 4 or periphery set as base case).

\begin{tabular}{|c|c|c|c|}
\hline \multirow[t]{2}{*}{ Variables } & \multicolumn{3}{|c|}{ Choice model } \\
\hline & Coef. & P-value & Elasticities* \\
\hline \multicolumn{4}{|l|}{ Cluster 1} \\
\hline Number of cars & -1.11139 & 0 & $-59 \%$ \\
\hline Number of children & -0.10856 & 0.356 & $-4 \%$ \\
\hline Number of workers/household & 0.091718 & 0.539 & $1 \%$ \\
\hline Age $<35$ & 0.582899 & 0.011 & $58 \%$ \\
\hline Age $50-64$ & 0.46013 & 0.098 & $34 \%$ \\
\hline Age $>64$ & 0.337822 & 0.625 & $37 \%$ \\
\hline Cons & -1.70909 & 0 & - \\
\hline \multicolumn{4}{|l|}{ Cluster 2} \\
\hline Number of cars & -1.14189 & 0 & $-60 \%$ \\
\hline Number of children & -0.28596 & 0 & $-20 \%$ \\
\hline Number of workers/household & 0.343653 & 0 & $29 \%$ \\
\hline Age $<35$ & 0.388765 & 0.002 & $30 \%$ \\
\hline Age $50-64$ & 0.396629 & 0.008 & $26 \%$ \\
\hline Age $>64$ & 0.392124 & 0.322 & $44 \%$ \\
\hline Cons & -0.07894 & 0.655 & - \\
\hline \multicolumn{4}{|l|}{ Cluster 3} \\
\hline Number of cars & -0.37394 & 0 & $-14 \%$ \\
\hline Number of children & -0.09006 & 0.075 & $-3 \%$ \\
\hline Number of workers/household & 0.113035 & 0.098 & $3 \%$ \\
\hline Age $<35$ & 0.178431 & 0.081 & $5 \%$ \\
\hline Age $50-64$ & 0.279148 & 0.025 & $12 \%$ \\
\hline Age $>64$ & -0.10312 & 0.779 & $-12 \%$ \\
\hline Cons & 0.091473 & 0.541 & - \\
\hline
\end{tabular}

* Elasticities represent the percentage change in the probability of choosing cluster $i$. ((new Prob of choosing cluster $i$ - base case prob of choosing cluster i)/ base prob of choosing cluster $i$ ). 
- Socio-economic attributes are also important factors in mode choice of individuals. In this regard, increasing income and age decrease the chance of using PT. Being male decreases the probability of selecting PT by 62 percent. A one-year increase in the age of the individual is associated with a 1 percent reduction in that individual's probability of selecting PT.

- Socio-economic characteristics are also important when it comes to selecting household residential location. The main factors affecting residential location choice are age, employment status, household structure, and number of cars at home. For instance, the empirical results show that young commuters to downtown, without children or car access prefer to reside near their workplaces (Clusters 1 and 2). Household car ownership has a negative effect on choosing any cluster other than the base case (Cluster 4 or periphery).

The implications of these empirical results can be viewed in different ways. Strategies that promote densification, increase land use mix, and improve transit accessibility in train catchment areas would positively influence downtown transit commuting. The results also suggest that increasing parking costs or reducing transit fares would encourage downtown commuting by public transit. More competitive travel times of transit services to downtown would also reduce car use for commuting purposes. These findings are consistent with previous work, indicating the sensitivity of downtown commuters to transit fees and parking pricing. Therefore, the combination of incentives and pricing strategies can help increase the share of PT. The results also shed some additional light on joint decision processes. Downtown commuters simultaneously decide the type of residential neighborhood and commuting transportation mode. The results also highlight the effect of regional trends in the population aging, economy, and household structure, which will certainly play a role in these two choices in the future.

It is also important to highlight some limitations of this work. For instance, this work is based on a subsample of commuter trips (cross-sectional data) from one city. Panel or longitudinal data and data from other cities would help validate these results. Secondly, what is focused on in this paper is the mode and location choice of individuals as indicators of mobility. However, other travel behavior outcomes such as number of trips, departure times, travel distances, or greenhouse gas emissions merit exploration to obtain more insights into commuter behavior.

\section{Acknowledgments}

The authors gratefully acknowledge the financial aid provided by FQRNT under the program "Recherche partenariat contribuant réduction et séquestration gaz effet de serre" and thank AMT and MTQ for providing the data necessary for this research.

\section{References}

Badoe, D. and E. Miller. 2000. Transportation-land use interaction: Empirical findings in North America, and their implications for modeling. Transportation Research Part D: Transport and Environment, 5(4):235-263. doi: 10.1016/S1361-9209(99)00036-X.

Bhat, C. R. and J. Y. Guo. 2007. A comprehensive analysis of built environment characteristics on household residential choice and auto ownership levels. Transportation Research Part B: Methodological, 41(5):506-526. doi: 10.1016/j.trb.2005.12.005.

Bianco, M. J. 2000. Effective transportation demand management: Combining parking pricing, transit incentives, and transportation management in a commercial district of Portland, Oregon. Transportation Research Record, 1711:46-54. doi: 10.3141/1711-07.

Boarnet, M. and S. Sarmiento. 1998. Can land-use policy really affect travel behaviour? a study of the link between non-work travel and land-use characteristics. Urban Studies, 35(7):1155-1169.

Brownstone, D. and T. F. Golob. 2009. The impact of residential density on vehicle usage and energy consumption. Journal of Urban Economics, 65(1):91-98. doi: 10.1016/j.jue.2008.09.002.

Cao, X., P. Mokhtarian, and S. Handy. 2008. Examining the impacts of residential self-selection on travel behavior: Methodologies and empirical findings. Research Report UCD-ITS-RR-08-25, Institute of Transportation Studies, University of California, Davis. URL http://pubs. its.ucdavis.edu/publication_detail.php?id=1194.

Cervero, R. 2002. Built environments and mode choice: Toward a normative framework. Transportation Research Part D: Transport and Environment, 7(4):265-284. doi: 10.1016/S1361-9209(01)00024-4.

Cervero, R. and K. Kockelman. 1997. Travel demand and the 3Ds: Density, diversity, and design. Transportation Research Part D: Transport and Environment, 2(3):199-219. doi: 10.1016/S1361-9209(97)00009-6. 
Cervero, R. and K. Wu. 1997. Influences of land use environments on commuting choices: An analysis of large U.S. metropolitan areas using the 1985 American Housing Survey. Working paper, University of California Transportation Center, Berkeley, CA.

Cloutier, M., P. Apparicio, and J. Thouez. 2007. GIS-based spatial analysis of child pedestrian accidents near primary schools in Montréal, Canada. Technical report, Institut national de la recherche scientifique.

Crane, R. 2000. The influence of urban form on travel: An interpretive review. Journal of Planning Literature, 15(1):3-23. doi: 10.1177/08854120022092890.

Crane, R. and R. Crepeau. 1998. Does neighborhood design influence travel behavior? a behavioral analysis of travel diary and GIS data. Technical Report UCI-ITS-AS-WP98-4, University of California, Irvine: Center for Activity Systems Analysis. URL http://escholarship.ucop.edu/uc/ item/5qq985sv.

Deb, P. and P. Seck. 2009. Internal migration, selection bias and human development: Evidence from Indonesia and Mexico. Human Development Research Paper No. 31, United Nations Development Programme, Human Development Report Office. URL http://hdr.undp.org/en/ reports/global/hdr2009/papers/HDRP_2009_31.pdf.

Deb, P. and P. K. Trivedi. 2006. Specification and simulated likelihood estimation of a non-normal treatmentoutcome model with selection: Application to health care utilization. Econometrics Journal, 9(2):307-331. doi: 10.1111/j.1368-423X.2006.00187.x.

Eluru, N., C. R. Bhat, R. M. Pendyala, and K. C. Konduri. 2010. A joint flexible econometric model system of household residential location and vehicle fleet composition/usage choices. Transportation, 37(4):603-626. doi: 10.1007/s11116-010-9271-3.

Ewing, R. and R. Cervero. 2001. Travel and the built environment: A synthesis. Transportation Research Record, 1780:87-114. doi: 10.3141/1780-10.

Ewing, R. and R. Cervero. 2010. Travel and the built environment. Journal of the American Planning Association, 76(3):265-294. doi: 10.1080/01944361003766766.

Ewing, R., P. Haliyur, and G. W. Page. 1994. Getting around a traditional city, a suburban planned unit development, and everything in between. Transportation Research Record, 1466:53-62.

Frank, L. D. and G. Pivo. 1994. Impacts of mixed use and density on the utilization of three modes of travel: Singleoccupant vehicle, transit and walking. Transportation Research Record, 1466:44-52.
Frank, L. D., T. L. Schmid, J. F. Sallis, J. Chapman, and B. E. Saelens. 2005. Linking objectively measured physical activity with objectively measured urban form: Findings from SMARTRAQ. American Journal of Preventive Medicine, 28(2, Supplement 2):117-125. doi: 10.1016/j.amepre.2004.11.001.

Gómez-Ibáñez, J. A., M. G. Boarnet, D. R. Brake, R. Cervero, A. Cotugno, and A. D. et al. 2009. Driving and the built environment: The effects of compact development on motorized travel, energy use, and CO 2 emissions. Special Report 298, Transportation Research Board.

Handy, S. 1996. Methodologies for exploring the link between urban form and travel behavior. Transportation Research Part D: Transport and Environment, 1(2):151-165. doi: 10.1016/S1361-9209(96)00010-7.

Handy, S., X. Cao, and P. Mokhtarian. 2005. Correlation or causality between the built environment and travel behavior? evidence from Northern California. Transportation Research Part D: Transport and Environment, 10(6):427-444. doi: 10.1016/j.trd.2005.05.002.

Hensher, D. A. and J. King. 2001. Parking demand and responsiveness to supply, pricing and location in the sydney central business district. Transportation Research Part A: Policy and Practice, 35(3):177-196. doi: 10.1016/S09658564(99)00054-3.

Hess, D. B. 2001. The effects of free parking on commuter mode choice: Evidence from travel diary data. Working paper, Lewis Center for Regional Policy Studies, University of California, Los Angeles.

Kitamura, R., P. Mokhtarian, and L. Daidet. 1997. A microanalysis of land use and travel in five neighborhoods in the San Francisco Bay area. Transportation, 24(2):125-158.

Kockelman, K. M. 1997. Travel behavior as a function of accessibility, land use mixing, and land use balance: Evidence from the San Francisco Bay area. Transportation Research Record, 1607:116-125. doi: 10.3141/1607-16.

Lin, J. and L. Long. 2008. What neighborhood are you in? Empirical findings of relationships between household travel and neighborhood characteristics. Transportation, 35(6):739-758. doi: 10.1007/s11116-008-9167-7.

Miranda-Moreno, L., L. Bettex, S. A. H. Zahabi, T. Kreider, and P. Barla. 2011. Simultaneous modeling of endogenous influence of urban form and public transit accessibility on distance traveled. Transportation Research Record, 2255:100-109. doi: 10.3141/2255-11.

Rajamani, J., C. R. Bhat, S. Handy, S. Knaap, and Y. Song. 2003. Assessing impact of urban form measures on nonwork trip mode choice after controlling for demographic 
and level-of-service effects. Transportation Research Record, 1831:158-165. doi: 10.3141/1831-18.

Riva, M., P. Apparicio, L. Gauvin, and J. Brodeur. 2008. Establishing the soundness of administrative spatial units for operationalising the active living potential of residential environments: An exemplar for designing optimal zones. International Journal of Health Geographics, 7(1):43-55. doi: 10.1186/1476-072X-7-43.

Rodriguez, D. A. and J. Joo. 2004. The relationship between non-motorized mode choice and the local physical environment. Transportation Research Part D: Transport and Environment, 9(2):151-173. doi: 10.1016/j.trd.2003.11.001.

Statistics Canada. 2001. Census preview of products and services 2003.

Theil, H. and A. J. Finizza. 1971. A note on the measurement of racial integration of schools by means of informational concepts. Journal of Mathematical Sociology, 1(2):187-193. doi: 10.1080/0022250X.1971.9989795.

Transportation Research Board. 2009. Driving and the built environment: The effects of compact development on motorized travel, energy use, and CO 2 emissions. Special Report 298, National Research Council, Washington, DC.

Washbrook, K., W. Haider, and M. Jaccard. 2006. Estimating commuter mode choice: A discrete choice analysis of the impacts of road pricing and parking charges. Transportation, 33(6):621-639. doi: 10.1007/s11116-005-5711-x.

Wilson, R. W. 1992. Estimating the travel and parking demand effects of employer-paid parking. Regional Science and Urban Economics, 22(1):133-145. doi: 10.1016/0166-0462(92)90029-Z.

Zhang, M. 2004. The role of land use in travel mode choice: Evidence from Boston and Hong Kong. Journal of the American Planning Association, 70(3):344-360. doi: 10.1080/01944360408976383. 